\title{
Penyulingan Minyak Kayu Putih (Melaleuca cajuputi) dengan Suhu yang Berbeda
}

\author{
Cajuputi (Melaleuca cajuputi) Essential Oil Distillation by Using Different Temperatures \\ Farida Aryani* \\ Jurusan Teknologi Pertanian, Politeknik Pertanian Negeri Samarinda \\ JI.Sam Ratulangi Kampus Gunung Panjang, Samarinda Seberang, PO BOX 192 Samarinda, \\ Kalimantan Timur, Indonesia \\ *Corresponding Author: ary_ani02@yahoo.com
}

\begin{abstract}
ABSTRAK
Melaleuca cajuputi merupakan salah satu tumbuhan penghasil minyak atsiri. Sejak jaman dahulu minyak kayu putih digunakan sebagai obat tradisional, karena baunya yang khas minyak kayu putih digunakan juga sebagai bahan pembuat aroma terapi untuk relaksasi. Tujuan penelitian ini adalah untuk mengetahui rendemen dan kualitas minyak kayu putih berdasarkan perbedaan suhu penyulingan. Penyulingan menggunakan alat berupa ketel dengan menggunakan metode penyulingan uap dan air dengan menggunakan perbedaan suhu yaitu $150^{\circ} \mathrm{C}$ dan $200^{\circ} \mathrm{C}$. Selanjutnya dilakukan penghitungan rendemen dan pengujian kualitas yang meliputi Spesific Gravity, indeks bias, dan analisis kandungan senyawa kimia menggunakan GCMS. Hasil penelitian menggunakan suhu penyulingan $150^{\circ} \mathrm{C}$ diperoleh rendemen sebesar $1.99 \%$, spesific grafity 0.9038 , indeks bias 1.464 ,dan analisis GC-MS untuk senyawa aktif 1.8 cineol memiliki $54.56 \%$ area. Sedangkan penyulingan pada suhu $200^{\circ} \mathrm{C}$ memperoleh rendemen sebesar $1.68 \%$, spesific grafity 0.9088 , indeks bias 1.465 , dan senyawa aktif 1.8 Sineol sebesar $53.67 \%$ area.
\end{abstract}

Kata kunci : Minyak atsiri, Melaleuca cajuputi, penyulingan, rendemen, GC-MS

\begin{abstract}
Melaleuca cajuputi is one of essential oil producing plants. Since ancient times, cajuput oil has been used as traditional medicine because of its distinctive smell. Cajuput oil is also used as an ingredient in aromatherapy for relaxation. The purpose of this study was to determine the yield and quality of cajuput oil based on differences distillation temperature. Distillation is carried out using a kettle with steam and water distillation method and temperature differences are $150^{\circ} \mathrm{C}$ and $200^{\circ} \mathrm{C}$. Calculation and quality testing are carried out which include specific gravity, refractive index, and analisys of chemical compounds using GC-MS. The distillation process at temperature $150^{\circ} \mathrm{C}$ obtained $1.99 \%$, a specific gravity of 0.9038 , a refraktiv index of 1.464 , and CG-MS analysis for active compound $1.8 \mathrm{cineol}$ which as area of $54.56 \%$. Meanwhile distillation at $200^{\circ} \mathrm{C}$ obtained $1.68 \%$, a specific gravity of 0.9088 , a refractive index of 1.465 , active compound 1.8 Cineol with and area of $53.67 \%$. From the study aboveit can beconcluded that distillation at $150^{\circ} \mathrm{C}$ give better yield compared to distillation at $200^{\circ} \mathrm{C}$.
\end{abstract}

Keywords : Essential oils, Melaleuca cajuputi, Distillation, yield, GC-MS

\section{PENDAHULUAN}

Tanaman kayu putih (Melaleuca cajuputi) merupakan salah satu tanaman penghasil minyak atsiri yang penting bagi industri minyak atsiri di Indonesia. Sebagai salah satu tanaman penghasil produk hasil hutan bukan kayu, tanaman kayu putih memiliki prospek cukup baik untuk dikembangkan (Alam dkk.,2019).

Potensi tanaman kayu putih di Indonesia cukup besar mulai dari daerah Maluku, Nusa Tenggara Timur, Sulawesi Tenggara, Bali dan Papua yang berupa hutan alam kayu putih. Sedangkan yang berada di 
Jawa Timur, Jawa Tengah dan Jawa Barat berupa hutan tanaman kayu putih (Mulyadi, 2005).s

Minyak kayu putih merupakan salah satu jenis minyak atsiri yang banyak digunakan untuk bahan berbagai produk kesehatan atau farmasi sehingga minyak kayu putih menjadi produk yang banyak dicari. Kebutuhan minyak kayu putih saat ini semakin meningkat dengan semakin berkembangnya variasi dari pemanfaatan minyak kayu putih. Menurut Rimbawanto dan Susanto (2004), suplai tahunan minyak kayu putih yang dibutuhkan Indonesia sebesar \pm 6000 ton/tahun sedangkan Indonesia sendiri hanya mampu menyuplai sebesar \pm 3500 ton/tahun dan kekurangannya dipenuhi dengan impor minyak ekaliptus dari Negara Cina.

Menurut Rimbawanto dan Susanto (2004) dalam Helfiansyah, dkk.,(2013) berdasarkan data dari berbagai pabrik minyak kayu putih yang ada di Indramayu, gundih, Paliyan Gunung Kidul, dan Ponorogo menunjukkan bahwa rendemen berkisar antara 0,6-1,0 sedang kadar Sineol berkisar antara $55-65 \%$. Dari data yang dipaparkan belum diketahui secara pasti teknik destilasi yang paling tepat untuk menghasilhan rendemen minyak kayu putih yang tinggi.

Produksi minyak kayu putih dipengaruhi oleh beberapa faktor meliputi pengisian daun dalam ketel, varietas pohon kayu putih, penyimpanan daun, teknik penyulingan, dan umur daun. Faktor-faktor inilah yang diduga berpengaruh terhadap rendemen dan mutu minyak kayu putih yang hasilkan (Guenther, 2011), pentingnya peranan minyak kayu putih dan di sisi lain kebutuhan akan minyak kayu putih di Indonesia belum sepenuhnya terpenuhi, penelitian ini dilakukan untuk mendapatkan hasil maksimal dari proses penyulingan minyak kayu putih.

\section{BAHAN DAN METODE}

\section{A. Bahan}

Bahan yang digunakan dalam penelitian ini adalah daun Melaleuca cajuputi, aluminium foil, MgSO4, aquades. Peralatan yang digunakan pada penelitian ini adalah : satu unit alat destilasi, , corong pemisah, timbangan manual, timbangan analitik, piknometer, refraktometer.

\section{B. Prosedur Penelitian}

Prrosedur kerja penelitian adalah sebagai berikut (Ma'mun,2015).

\section{Pengambilan Bahan Baku}

Bahan baku yang digunakan diambil disekitar kampus Politeknik Pertanian Negeri Samarinda.

\section{Proses Pengeringan dan Pelayuan}

Bahan baku daun kayu putih dikeringkan dengan cara diletakkan di dalam ruangan yang mempunyai sirkulasi udara cukup baik. Pengeringan dilakukan selama tiga hari dengan sesekali dibolak balik agar proses pengeringannya merata.

\section{Proses Penyulingan}

Proses penyulingan menggunakan metode penyulingan uap dan air (Water and Steam Distillation). Adapun langkah-langkah proses penyulingan adalah sebagai berikut:

Menyiapkan peralatan penyulingan yang terdiri dari ketel suling, kondensor, dan kompor.

Mengisi ketel dengan air sampai permukaannya tidak jauh dari bagian bawah saringan dimana bahan di tempatkan, kemudian memasukkan bahan baku kedalam ketel penyulingan.

Memasang tutup ketel pada alat penyulingan dan dikaitkan dengan baut. Pemasangan baut ketel dilakukan dengan hati-hati agar tidak terdapat celah yang dapat menyebabkan keluarnya uap.

Saat air direbus dan mendidih, uap yang terbentuk akan lewat melalui saringan lubang-lubang kecil dan melewati celah-celah bahan. Minyak atsiri dalam bahan pun akan ikut bersama uap panas tersebut menuju kondensor (pendingin) sehingga terjadi pengembunan (uap air dan minyak akan mengembun). Setelah 1 jam, keluar embun pada kondensor yang diikuti dengan tetesan air yang tercampur minyak. Pada ujung kondensor diletakkan erlenmeyer untuk menampung air beserta minyak yang keluar, mulut erlenmeyer ditutup aluminium foil supaya tidak ada celah untuk menguapnya minyak atsiri. Penyulingan dilaksanakan selama 3-4 jam. Lama penyulingan dimulai ketika minyak keluar pertama kali sampai minyak tidak keluar lagi. 
4 Proses Pemisahan Air dan Minyak Kayu Putih

Proses pemisahan air dan minyak atsiri menggunakan alat corong pemisah. Pemisahan ini dilakukan berdasarkan perbedaan bobot jenisnya. . Selanjutnya minyak ditimbang untuk mengetahui beratnya.

\section{Proses Pemurnian Minyak.}

Minyak atsiri yang diperoleh dibebaskan dari sisa air. Proses pemurnian minyak menggunakan bahan kimia $\mathrm{MgSO}_{4}$ (magnesium sulfat). berfungsi sebagai pengikat air dan kotoran yang masih tercampur pada minyak.

\section{Menghitung Rendemen}

Menurut Harris (1998), rendemen dihitung berdasarkan perbandingan antar output dan input dalam persen (\%).Pengertian ini dapat dirumuskan sebagai berikut:

$$
\text { Rendemen }=\frac{\text { Output }}{\text { Input }} \times 100 \%
$$

Keterangan:

Output = berat minyak atsiri yang dihasilkan Input = berat bahan baku

\section{Pengujian Kualitas}

Pengujian kualitas meliputi bobot jenis dan indeks bias menggunakan SNI 3954:2014 minyak kayu putih dan analisis komponen senyawa menggunakan alat GCMS.

\section{Bobot Jenis}

Piknometer kosong ditimbang dalam keadaan bersih $(m)$, setelah itu diisi dengan aquades hingga penuh hindari gelembung udara. Selanjutnya piknometer ditutup dan dikeringkan bagian luarnya kemudian ditimbang $\left(m_{1}\right)$. Piknometer dikosongkan kemudian dicuci, dengan etanol dan aseton lalu dikeringkan. Piknometer diisi dengan minyak kayu putih kemudian ditutup lalu dikeringkan dan ditimbang $\left(m_{2}\right)$. Mencatat suhu pada saat pengerjaan (SNI 3954:2014).

Bobot jenis pada suhu pengerjaan

$\mathrm{d} \frac{T 1}{T 1}=\frac{m 2-m}{m 1-m}$
Bobot jenis pada suhu standar:

$\mathrm{d} \frac{T}{T}=\mathrm{d} \frac{T 1}{T 1}+0,0007\left(T_{1}-T\right)$

$m$ : bobot piknometer kosong $(\mathrm{g})$

$m_{1}$ : bobot piknometer + akuades $(\mathrm{g})$

$m_{2}$ : bobot piknometer + minyak $(\mathrm{g})$

$T_{1}$ : suhu pengerjaan $\left({ }^{\circ} \mathrm{C}\right)$

$T$ : suhu referensi $20\left({ }^{\circ} \mathrm{C}\right)$

$\mathrm{d} \frac{T 1}{T 1}$ :bobot jenis pada suhu pengerjaan

$\mathrm{d}_{T}^{T}$ :bobot jenis pada suhu $20^{\circ} \mathrm{C}$

0.0007 : faktor koreksi

\section{Indeks Bias}

Penetapan indeks bias minyak atsiri dilakukan dengan menggunakan alat refraktometer Abbe. Kaca prisma pada alat refraktometer dibersihkan menggunakan etanol kemudian dikeringkan. Sampel minyak kayu putih disiapkan kemudian diteteskan pada prisma. Kondisi alat dan sampel pada suhu ruang saat pengerjaan $20^{\circ} \mathrm{C} \pm 2^{\circ} \mathrm{C}$. Indeks bias dibaca pada suhu pengerjaan (SNI 3954:2014).

Indeks bias $\mathrm{n} \frac{T}{D}=\mathrm{n} \frac{T 1}{D}+0,0004\left(\mathrm{~T}_{1}-\mathrm{T}\right)$

$\mathrm{n} \frac{T 1}{D}$ : indeks bias pada suhu pengerjaan

$\mathrm{n} \frac{T}{D}$ : Indeks bias pada suhu $20^{\circ} \mathrm{C}$

$T_{1}$ : suhu pengerjaan $\left({ }^{\circ} \mathrm{C}\right)$

$T$ : suhu referensi $\left(20^{\circ} \mathrm{C}\right)$

0,0004 : faktor koreksi

\section{Analisis GC-MS}

Identifikasi sineol dilakukan di laboratorium Instrument Politeknik Negeri Ujung Pandang menggunakan alat GCMSQP2010 ULTRA ZSHIMADSU. Komputerisasi untuk pengolahan data akan membantu menafsirkan hasil analisis yang tersedia dalam library alat tersebut. Dari kromatogram dapat diperoleh informasi mengenai jumlah komponen kimia yang terdapat dalam sampel minyak yang dianalisis, dengan ditunjukkan dalam jumlah puncak yang terbentuk pada kromatogram (Helfiansyah,dkk.,2013).

\section{HASIL DAN PEMBAHASAN}

\section{Rendemen}

Hasil analisis rendemen minyak kayu putih dengan metode penyulingan uap dan 
air dengan perbedaan suhu penyulingan dapat dilihat pada tabel berikut :

Tabel 1. Hasil Analisa Rendemen Minyak Kayu Putih

\begin{tabular}{c|c}
\hline Suhu Distilasi & Rendemen $(\%)$ \\
\hline $150{ }^{\circ} \mathrm{C}$ & 1.99 \\
\hline $200{ }^{\circ} \mathrm{C}$ & 1.68 \\
\hline
\end{tabular}

Dari hasil yang disajikan pada Tabel 1 diketahui bahwa nilai rendemen penyulingan minyak kayu putih yang menggunakan suhu $150^{\circ} \mathrm{C}$ pada saat penyulingan menghasilkan rendemen yang lebih besar dibanding penyulingan dengan suhu $200^{\circ} \mathrm{C}$. keadaan ini diduga pada saat proses penyulingan dengan suhu tinggi ada minyak yang menguap akibat kurang maksimalnya kerja kondensor mendinginkan minyak sehingga kondensasi tidak berjalan sempurna. Namun demikian rendemen yang dihasilkan sesuai dengan data yang dikeluarkan oleh Perhutani (2012) yang menyatakan bahwa rendemen yang dihasilkan oleh Melaleuca cajuputi berkisar antara $1-2 \%$.

\section{Bobot Jenis}

Bobot jenis merupakan perbandingan berat suatu bahan dengan berat air dalam volume yang sama. Bobot jenis merupakan merupakan salah satu kriteria penting dalam menentukan mutu dan kemurnian minyak atsiri. Nilai bobot jenis minyak kayu putih yang disajikan pada Tabel 3 terlihat bahwa bobot jenis minyak kayu putih yang didestilasi pada suhu $150^{\circ} \mathrm{C}$ mempunyai nilai sedikit lebih rendah dibanding minyak kayu putih yang didestilasi pada suhu $200^{\circ} \mathrm{C}$. Keadaan ini diduga adanya senyawa dengan bobot molekul yang lebih besar yang terdapat pada minyak dengan pemanasan suhu $200^{\circ} \mathrm{C}$. Slamet dkk.,(2019) menyaatakan bahwa semakin banyak fraksi berat yang terkandung, maka bobot jenisnya akan semakin tinggi. Fraksi berat ini dipengaruhi oleh panjangnya rantai molekul senyawa yang terkandung dalam minyak. Panjangnya molekul suatu senyawa berpengaruh pada bobot molekul senyawa tersebut. Senyawa golongan sesquiterpen termasuk fraksi berat jika dibandingkan dengan golongan monoterpen.
Tabel 2. Hasil Analisa Bobot Jenis

\begin{tabular}{cc}
\hline Suhu Distilasi & Bobot jenis $\left(20^{\circ} \mathrm{C}\right)$ \\
\hline $150^{\circ} \mathrm{C}$ & 0.9038 \\
\hline $200^{\circ} \mathrm{C}$ & 0.9088 \\
\hline
\end{tabular}

Tabel 3. Persyaratan Umum Pada Minyak Kayu Putih (SNI 3954:2014)

\begin{tabular}{lll}
\hline No & Parameter & \multicolumn{1}{c}{ Persyaratan } \\
\hline 1 & Warna & $\begin{array}{l}\text { Tidak berwarna, } \\
\text { kekuningan atau } \\
\text { kehijauan dan jernih } \\
\text { Khas kayu putih }\end{array}$ \\
2 & Bau & $0.900-0.930$ \\
3 & $\begin{array}{l}\text { Bobot jenis } \\
20^{\circ} \mathrm{C}\end{array}$ \\
4 & $\begin{array}{l}\text { Indeks bias } \\
\text { nD }{ }^{20}\end{array}$ & $1.450-1.470$ \\
5 & $\begin{array}{l}\text { Kelarutan } \\
\text { dalam etanol }\end{array}$ & Jernih \\
& $\begin{array}{l}80 \% \\
6\end{array}$ & Putaran optis \\
& & $(-) 4^{\circ}$ s.d. $0^{\circ}$ \\
\hline
\end{tabular}

\section{Indeks Bias}

Indeks bias diperoleh jika cahaya melewati media kurang padat ke media lebih padat, maka sinar akan membelok atau membias menuju garis normal. Indeks bias Berdasarkan hasil analisis sebagaimana tercantum dalam Tabel 2 diketahui bahwa indeks bias minyak kayu putih yang didestilasi dengan suhu $150^{\circ} \mathrm{C}$ dan $200^{\circ} \mathrm{C}$ tidak terlihat perbedaan yang berarti, indeks bias dari kedua perlakuan masuk dalam standar SNI 3954:2014 yang mensyaratkan nilai indeks bias pada kisaran 1,450 - 1,470. Indeks bias diperoleh jika cahaya melewati media kurang padat ke media lebih padat, maka sinar akan membelok atau membias menuju garis normal. Menurut (Arnita, 2011), senyawa organik mempunyai nilai indeks bias sebanding dengan panjang rantai karbon atau rantai siklis yang menyusunnya dan jumlah ikatan rangkap yang terdapat pada senyawa tersebut.

Tabel 4 Hasil Analisis Indeks Bias

\begin{tabular}{cc}
\hline Suhu Distilasi & Indeks Bias $\left(20^{\circ} \mathrm{C}\right)$ \\
\hline $150^{\circ} \mathrm{C}$ & 1.464 \\
\hline $200^{\circ} \mathrm{C}$ & 1.465 \\
\hline
\end{tabular}




\section{Analisis GC-MS}

Hasil analisis GC-MS seperti yang disajikan pada Gambar 1 dan Gambar 2 menunjukan bahwa pada masing-masing minyak dengan perbedaan suhu destilasi terdapat 20 komponen kimia yang dapat terindentifikasi. Senyawa aktif dari minyak kayu putih adalah 1,8 Sineol dari golongan monoterpen merupakan komponen terbesar dari minyak kayu putih yang didestilasi dengan suhu $150^{\circ} \mathrm{C}$ maupun $200^{\circ} \mathrm{C}$ dengan persen area masing-masing $54,56 \%$ dan $53,67 \%$ dengan waktu retensi masing-masing 3,633 dan 3,632 menit. Komponen mayor selanjutnya adalah3-Cyclohexene1methanolL,ALPH dari golongan terpenoid dengan waktu retensi 4,691 dan 4,683 dengan persen area masing-masing $17,83 \%$ dan $12,08 \%$. DLimonene dari golongan monoterpen dengan waktu retensi 3,595 dengan persen area sebesar $5,22 \%$ pada penyulingan dengan suhu $150^{\circ} \mathrm{C}$, sedang pada suhu $200^{\circ} \mathrm{C} 8,35 \%$ pada waktu retensi yang sama.

Dari golongan sesquiterpen Caryopyllenene memiliki persen area lebih kecil yaitu 3,04\% pada suhu destilasi $150^{\circ} \mathrm{C}$ dibanding dengan suhu destilasi $200^{\circ} \mathrm{C}$ sebesar $6,44 \%$. Alpha caryophyllenene dengan area 2,75\% ada pada pemanasan $200^{\circ} \mathrm{C}$ dan tidak terdeteksi pada suhu $150^{\circ} \mathrm{C}$. Gamma eudesmol dengan area sebesar $2,22 \%$ dan $1,14 \%$ dan $(+)$ Beta eudesmol masingmasing memiliki area sebesar $6,44 \%$ dan $3,22 \%$ untuk suhu destilasi $150^{\circ} \mathrm{C}$ dan $200^{\circ} \mathrm{C}$. Secara umum komponensenyawa yang terdapat pada minyak kayu putih tidak signifikan, terutama pada senyawa aktiv yaitu 1,8 Cineol. Kedua minyak atsiri ini tergolong mutu Pertama pada persyaratan khusus SNI minyak kayu putih.
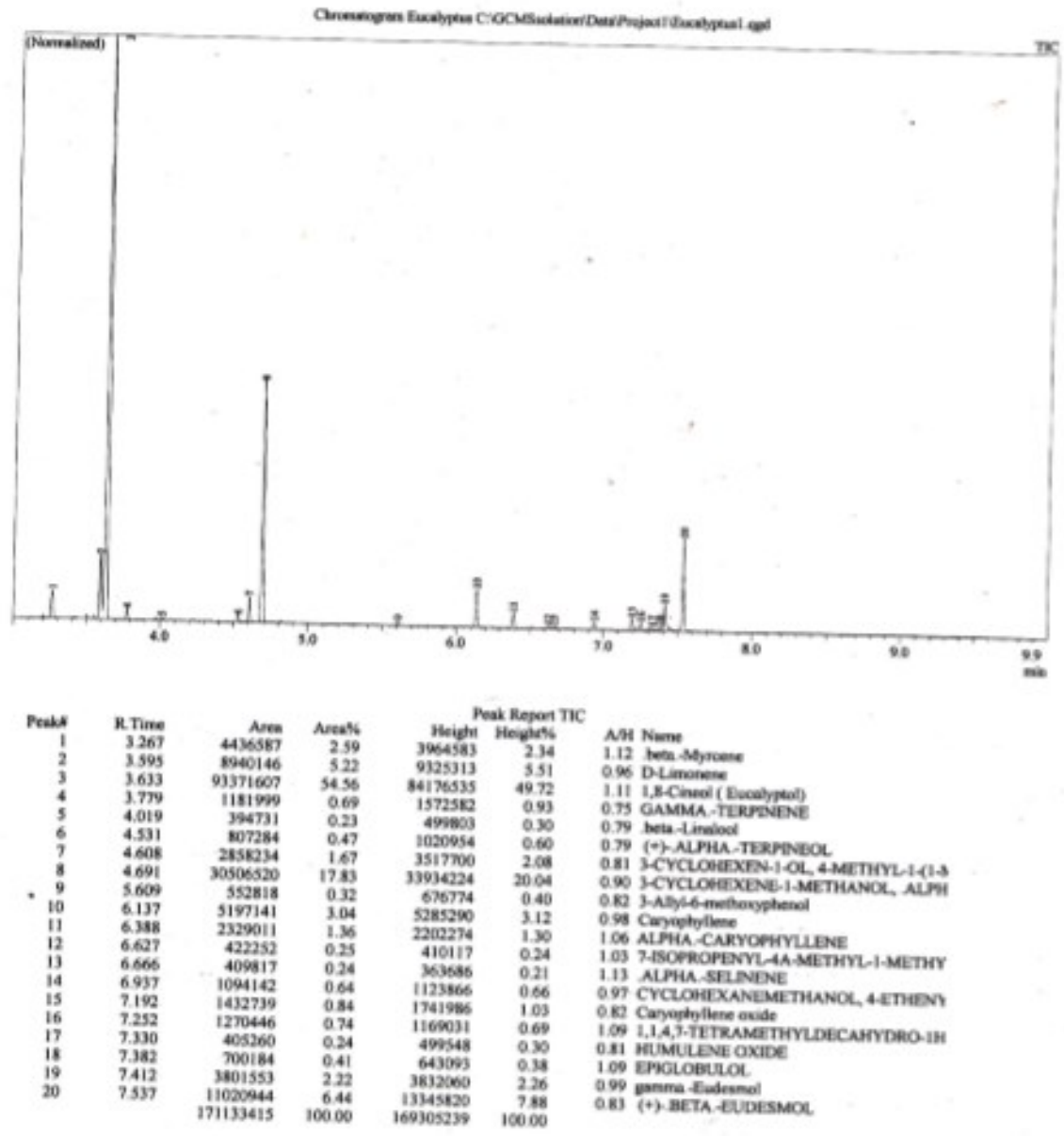

Gambar 1. Hasil Analisis GCMS Minyak Kayu Putih Dengan Suhu Destilasi 150 


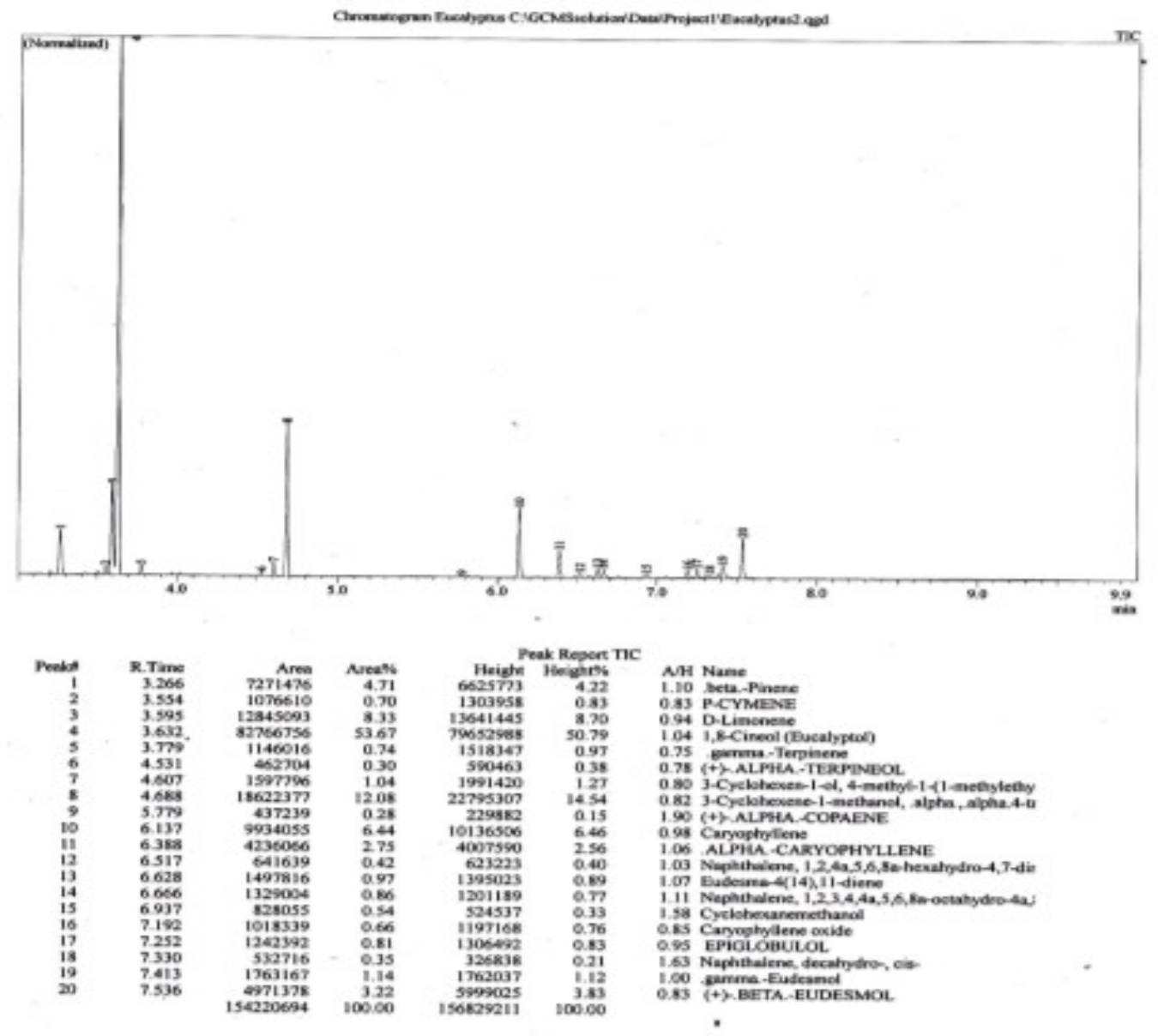

Gambar 2. Hasil Analisis GCMS Minyak Kayu Putih Dengan Suhu Destilasi $200^{\circ} \mathrm{C}$

\section{KESIMPULAN}

Rendemen minyak kayu putih pada suhu destilasi $150^{\circ} \mathrm{C}$ memberikan nilai yang tinggi yaitu sebesar 1,99\%. Untuk sifat fisika yaitu bobot jenis dan indeks bias, baik penyulingan dengan suhu $150^{\circ} \mathrm{C}$ maupun $200^{\circ} \mathrm{C}$ keduanya masuk dalam standar mutu SNI 3954:2014. Kadar Sineol pada suhu destilasi $150^{\circ} \mathrm{C}$ adalah sebesar $54,56 \%$, dan suhu destilasi $200^{\circ} \mathrm{C}$ sebesar $53,67 \%$, keduanya masuk dalam kelas mutu Pertama dalam persyaratan khusus minyak kayu putih SNI 3954:2014.

\section{DAFTAR PUSTAKA}

Alam,S.N, Pujiarti.R, Kasmudjo 2019. Effect of Distillation Tank Density and Storage Time on the Quality and Chemical Composition of Cajuput Oil. Wood Research Journal Vol.10 No.1

Arnita, 2011. Pengaruh Varietas dan Kerapatan Daun Kayu Putih dalam Katel terhadap Rendemen dan Mutu Minyak Kayu Putih. Departemen hasil hutan Fakultas Kehutanan Institut Pertanian Bogor, Bogor.

Badan Standarisasi Nasional. 2014. Standar Nasional Indonesia. Minyak Kayu Putih. SNI 3954:2014

Guenther, E. 2011. "Minyak Atsiri Jilid 1", Ul-Press, Universitas Indonesia Jakarta.

Harris, R. 1998. Perhitungan Rendemen. Penebar Swadaya, Jakarta.

Helfiansyah.R, Sastrohamidjojo.H, Riyanto. 2013. Isolasi, Identifikasi 
Dan Pemurnian Senyawa 1,8

Sineol Minyak Kayu Putih (melaleuca leucadendron). ASEAN Journal of System Engineering, Vol. 1, No.1.

Ketaren, S. 1985. Pengantar Teknologi Minyak Atsiri. Balai Pustaka Jakarta.

Ma'mun. 2015. Sirkuler. Petunjuk Teknis Penanganan Bahan Dan Penyulingan Minyak Atsiri. Balai Penelitian Tanaman Rempah dan Obat.

Mulyadi, T. 2005. Studi pengelolaan kayu putih Melaleuca leucadendron Linn. Berbasis ekosistem di BDH Karangmojo, Gunung Kidul, Yogyakarta. Thesis Program Pascasarjana Fakultas Kehutanan Universitas Gadjah Mada.

Perhutani, (2012) Data Hasil Produksi Perusahaan Minyak Kayu Putih (PMKP) Jatimunggul, Perhutani Unit III Jawa Barat. Tidak diterbitkan.

Rimbawanto, A., Susanto, M. 2004. Pemuliaan Melaleuca cajuputi subsp cajuputi untuk Pengembangan Industri Minyak Kayu Putih Indonesia. Prosiding Ekspose Hasil Litbang Bioteknologi dan Pemuliaan Tanaman Hutan Hal.83-92. Pusat Penelitian dan Pengembangan Bioteknologi dan Pemuliaan Tanaman Hutan. Yogyakarta.

Slamet, Ulyarti. Rahmi.S.L. 2019. Pengaruh Lama Fermentasi Daun Nilam Menggunakan Ragi Tempe Terhadap Rendemen Dan Mutu Fisik Minyak Nilam.

Utomo,D.B.G. Mujiburohman,M. 2019. Pengaruh Kondisi Daun Dan Waktu Penyulingan Terhadap Rendemen Kayu Putih. POLBAN. $10^{\text {th }}$ Industrial Research Workshop and National Seminar. 